\title{
Vasos comunicantes entre cartografía, historia y geopolítica en el Mapa de la República de la Nueva Granada (1847) de Joaquín Acosta
}

\author{
Connections between cartography, history and geopolitics on the \\ Joaquín Acosta’s Mapa de la República de la Nueva Granada (1847)
}

\author{
LUCÍA DUQUE MUÑOZ \\ Universidad Nacional de Colombia
}

RESUMEN Durante su segunda estadía en Francia, Joaquín Acosta hizo imprimir en Paris el Mapa de la República de la Nueva Granada dedicado al barón de Humboldt (1847). Esta carta está entre las primeras del periodo nacional colombiano que conjuga información levantada por un granadino con la mayoría de conocimientos geográficos modernos existentes sobre el país. El mapa se centra en la geografía física, representando detalladamente litorales, relieve, hidrografía e innumerables poblaciones. Además de la información relativa a la geografía física, un aporte fundamental de esta carta es su propuesta de trazado de los límites del territorio granadino basada particularmente en documentos de finales del periodo colonial. La intención de este artículo es entonces explorar el método utilizado para la construcción del mapa, haciendo énfasis en la forma en que combina prácticas de cartógrafo e historiador.

Palabras-clave Joaquín Acosta - cartografía - historia - territorio nacional - Colombia siglo XIX.

\begin{abstract}
During his second visit to France, Joaquin Acosta published in Paris the Mapa de la República de la Nueva Granada dedicado al barón de Humboldt (1847). This map is among the first to incorporate topographical information collected by Acosta with the majority of geographical knowledge about the country at the moment. The map is focused on physical geography, depicting the coastlines, mountains, hydrography, and many towns and cities. In addition to the vast information related to physical geography, a major contribution of Acosta's map is that it represents the borders of the New Granada's national territory, particularly based on historical documents from the time of the late colonial period. The main purpose of this article is then to explore the method used by Acosta to produce this map, emphasizing on the way he brings together practices of both cartographers and historians.
\end{abstract}

Keywords Joaquin Acosta - cartography - history - national territory - Colombia 19th century. 


\section{Preámbulo}

En Colombia conocemos a Joaquín Acosta ante todo por su trabajo como historiador, autor del Compendio histórico del descubrimiento y colonización de la Nueva Granada publicado en 1848. Allí mismo, él afirma:

(...) nos ocuparemos en narrar lo que tiene relación con lo acontecido en el territorio que hoy comprende la República de Nueva Granada, país que ocupa la posición más importante de la América meridional, y que se extiende de las orillas del Orinoco hasta las costas del grande Océano, por diez y siete grados de longitud, y desde uno á trece grados de latitud, con cerca de doscientas leguas de costas en el Atlántico. ${ }^{1}$

Así, desde las primeras páginas de su reconocido Compendio, Acosta expresa su deseo de construir una imagen integral del territorio y de la naturaleza granadina. La geografía emerge entonces al interior de su mirada sobre la historia y, como se verá, además de cartógrafo y geógrafo, Acosta será también historiador. En ese sentido, su trabajo plantea múltiples canales comunicantes que transitan entre la historia y la geografía.

En efecto, fue de manera casi simultánea a la elaboración de su trabajo histórico, que Acosta empezó el proceso de edición del Mapa de la República de la Nueva Granada dedicado al Barón de Humboldt (París, 1847), durante su segunda estadía en Europa (1845-1849), viaje que tuvo lugar luego de haber ejercido diversas ocupaciones que le pusieron en contacto directo con la topografía, la naturaleza y la reflexión sobre los límites y fronteras del país. Acosta, ingeniero y militar, había sido también director de la Oficina de Caminos y Secretario de Relaciones Exteriores de la Nueva Granada en la década de 1840.

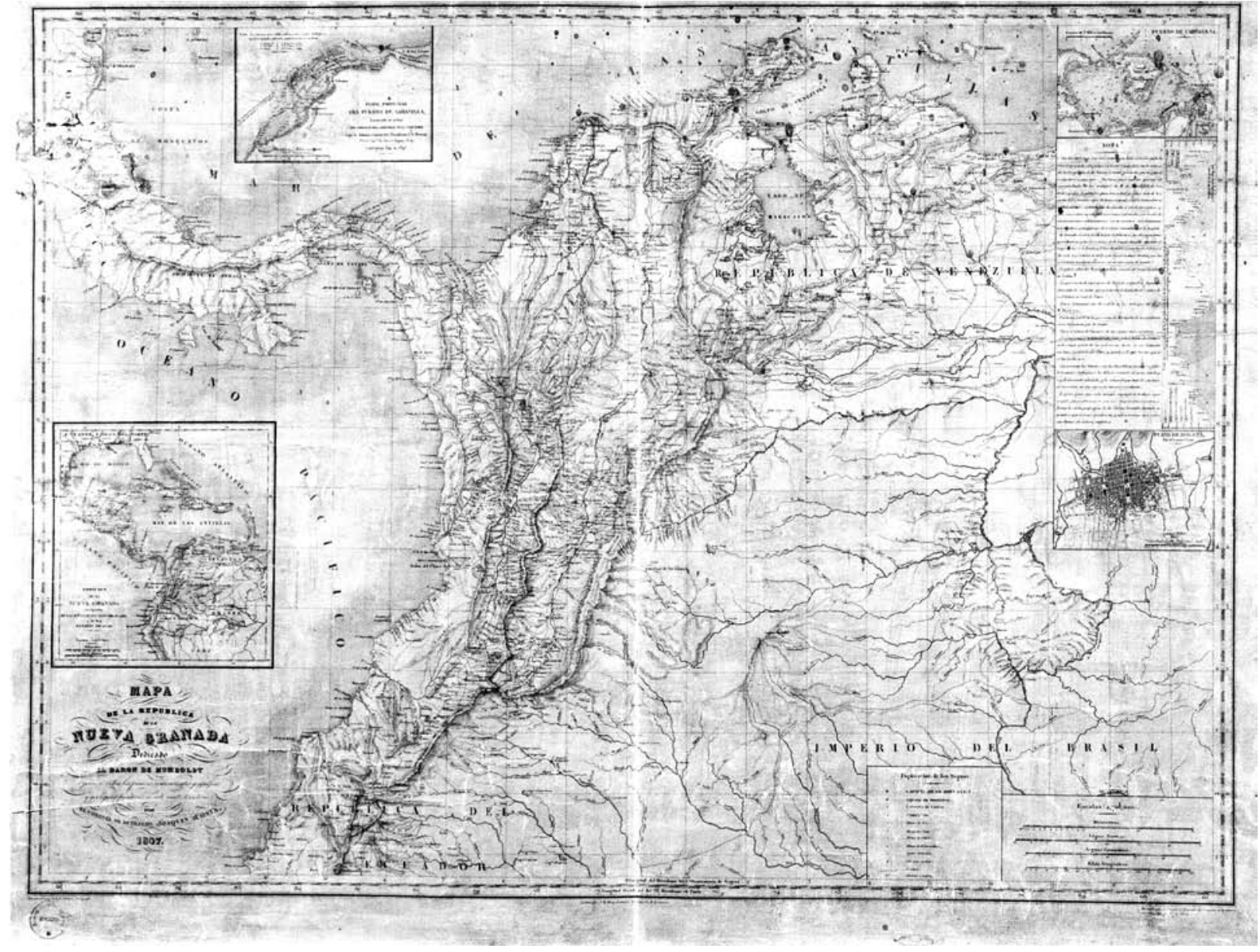

Mapa de la República de la Nueva Granada dedicado al barón de Humboldt (1847) por Joaquín Acosta. Archivo General de la Nación de Colombia. 
Su mapa de 1847 aparece, de alguna manera un poco aislado, entre dos coyunturas clave dentro de la cartografía colombiana: por una parte, el periodo de la llamada Gran Colombia (1819-1830) en el que se generan intentos importantes desde el Estado en su etapa fundacional por representar cartográficamente el territorio y, posteriormente, la década de 1850, en la cual la Comisión Corográfica va a cumplir un rol central en la construcción de un trazado cartográfico de la Nueva Granada. En ese sentido, he considerado importante indagar sobre los posibles vínculos de esta carta con momentos anteriores y posteriores de la cartografía colombiana, con el propósito de analizar qué diálogo se establece entre los distintos mapas nacionales. ¿Qué relaciones muestra entonces el trabajo cartográfico de Acosta con la discusión de temas que, para el momento, empiezan a ser relevantes como el de la problemática limítrofe, y ¿qué incidencia pudo haber jugado un mapa como éste, sobrio y escueto desde el punto de vista del diseño, sobre la cartografía de la época?

Efectivamente, debe tenerse presente que durante las décadas centrales del siglo XIX - desde finales de la década de 1840 hasta 1865 en la Nueva Granada (Estados Unidos de Colombia a partir de 1863) se elaboró un conjunto relativamente considerable de mapas nacionales: cerca de 6 mapas según lo que hemos podido encontrar en archivos. Con posterioridad a los trazados de José Manuel Restrepo y Joaquín Acosta, salieron a luz, entre otros, la Carta de la República de la Nueva Granada por Tomás Cipriano de Mosquera (1852), el Mapa arreglado al sistema federal por José María Samper (1858) y la Carta jeográfica de los Estados Unidos de Colombia por Manuel Ponce y Manuel María Paz, este último basado en los trabajos de Agustín Codazzi y la Comisión Corográfica (1865).

Su interés, además de precisar las coordenadas de la geografía física, era proyectar el trazado de las fronteras internas y externas del territorio, ligadas a una reflexión que puede considerarse de carácter geopolítico, en la que, si bien de manera incipiente, empezaban a esbozarse las nociones de límite y frontera, expresados a través de la cartografía. Así, a la reflexión sobre el lugar de las alturas y del clima, de las tierras altas y bajas en el proceso de civilización característica de trabajos como los de Francisco José de Caldas, ${ }^{2}$ se sumó poco a poco una discusión ligada a las distinciones entre el centro y las periferias, así como a la incorporación de los márgenes y las áreas de frontera al proyecto nacional. Sin embargo, resulta un poco paradójico entender la elaboración de mapas nacionales en un momento en el que difícilmente puede hablarse de un Estado nacional y en el que se tiende a la profundización de las autonomías regionales a partir de la aplicación del modelo federal en el país.

Es así como, dado que los límites no habían sido establecidos con claridad y no lograron ser ratificados sino hasta las primeras décadas del siglo XX, el propósito de estas cartas geográficas no fue, efectivamente, representar con precisión científica un territorio previamente definido. Más bien, la cartografía estaba cumpliendo el rol de promover lo que se consideraba "derechos e intereses territoriales" del Estado granadino frente a sus vecinos y hacer una proyección acerca de cómo debía ser el territorio nacional de cara al futuro. De otra parte, este proceso de representación cartográfica estaba inserto dentro de una estrategia incipiente pero que, de una u otra forma, expresaba el deseo civilizador del Estado y la intención de integrar algunas áreas ubicadas en los espacios más marginales y retirados de su geografía.

Así, por ejemplo, desde 1843, además de la división en Estados, Provincias, Cantones y Distritos, se crearon los llamados “Territorios Nacionales" definidos por la Constitución de 1853 como aquellas regiones "que no están pobladas por habitantes reducidos a la vida civil" o bien por la considerada "población salvaje 0 a medio camino de la civilización". Para dichos "Territorios", que abarcaban áreas principalmente selváticas, se dispuso de un régimen especial: no debían ser administrados por alcaldes ni gobernadores, sino por prefectos militares encargados de someter a control a la población nativa y fomentar, en lo posible, la colonización de estas zonas. Hacia mediados del siglo, en la Nueva Granada ya existían precisamente los Territorios de Bocas del Toro y del Darién en América Central, de la Guajira, de San Martín y Casanare en los Llanos Orientales y el Territorio de Caquetá hacia el sur-oriente del país. Sin embargo, la creación de estos territorios con carácter especial no implicó rápidamente procesos exitosos de colonización ni una mayor integración de estas áreas a las dinámicas económicas del país.

En ese sentido, la carta trazada por Joaquín Acosta aparece vinculada a un conjunto de temas entre los cuales sobresale la reciente aparición de problemas de orden limítrofe y geopolítico, asunto sumamente complejo que, desde nuestro punto de vista, él abordará desde una perspectiva en la cual suma las prácticas de cartógrafo e historiador. 


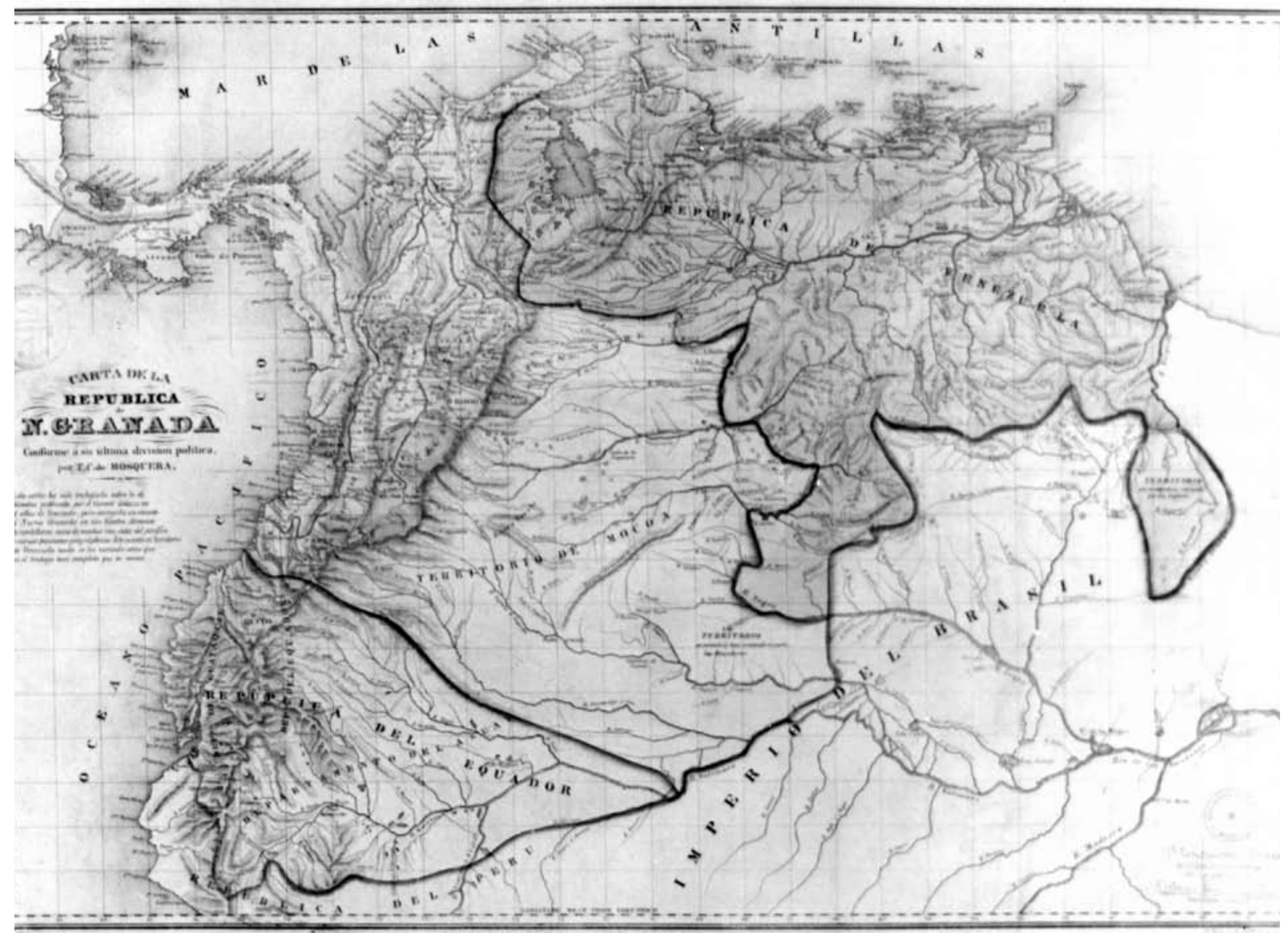

Carta de la República de la Nueva Granada (1852) por Tomás Cipriano de Mosquera. Archivo General de la Nación de Colombia.

\section{Método y fuentes en la elaboración del Mapa de la República de la Nueva Granada (1847)}

Para tratar de mostrar su posible influencia sobre la cartografía de mediados del siglo XIX, debemos empezar por entender, de manera muy general, cuál fue el método de construcción y la forma en la que se elaboró el mapa de 1847. Retomando las palabras de Numa Broc, este documento reúne lo que se ha llamado "trabajo de gabinete" o de escritorio y "trabajo de campo" o de terreno, combinación bastante frecuente en los levantamientos cartográficos de los siglos XVIII y XIX. ${ }^{4}$ En efecto, la carta retoma un amplio conjunto de medidas y coordenadas reunidas por el autor en sus trayectos a lo largo del territorio granadino, en particular en lo que se refiere a la región chocoana, recorrida por él durante trayectos militares que lo llevaron a remontar los Ríos Atrato, San Juan, Tamaná, Habitá e Ingará en el periodo de las guerras de independencia. ${ }^{5}$ Según lo consigna en una nota explicativa incluida en el mapa: "Los itinerarios militares que poseo y mis frecuentes viajes en la mayor parte de las provincias de la Nueva Granada me han suministrado datos y detalles de que hasta aquí no se ha hecho uso".

Su vida militar de las primeras décadas del siglo XIX había sido la vía para entrar en contacto directo con la geografía granadina, a lo que más adelante se sumó el ejercicio de cargos como el de Director de la Oficina de Caminos (1832) que lo mantuvo en relación con las características topográficas del país. Efectivamente, si bien son un poco dispersos y fragmentarios, son numerosos los párrafos en los que Acosta da testimonio de su interés por los viajes y el trabajo de campo como parte de su trabajo como cartógrafo y como historiador. Por ejemplo, refiriéndose al periodo de la conquista del área de la Nueva Granada en el prólogo de su Compendio histórico, relata que había tenido la fortuna de: 
(...) recorrer mucha parte de la Nueva Granada y de los lugares en donde ocurrieron los sucesos más importantes de aquel descubrimiento. En 1834 hice una excursión desde el valle del Socorro al del Magdalena con el distinguido y malogrado Doctor Céspedes. Allí vimos las selvas vírgenes, las raíces seculares entreveradas y los despeñaderos que opusieron tantos obstáculos a Gonzalo Jimenez de Quesada. ${ }^{6}$

Adicionalmente, pese al valor que otorga a sus propios trayectos en la elaboración del mapa de 1847, Acosta suma la investigación en fuentes de archivo e información proporcionada por una red de algunos de los más reconocidos científicos que habían hecho investigaciones en la Nueva Granada en el tránsito del periodo colonial al republicano. Entre ellos, Alejandro de Humboldt de quien tomó la base cartográfica, así como Jean Baptiste Boussingault, François Désiré Roulin y Mariano Rivero para el curso del Río Meta, miembros estos últimos de la llamada "Misión Zea". 7 Según afirma Acosta, Boussingault puso a su disposición "materiales inéditos" que consistían en "muchas posiciones calculadas por medio de observaciones astronómicas, un extenso nivelamiento barométrico y algunas direcciones calculadas con la brújula". ${ }^{8}$

En el recuadro explicativo incluido en la esquina superior derecha de la carta, el autor menciona entre sus fuentes para el dibujo del litoral Atlántico, los trazados cartográficos de Joaquín Francisco Fidalgo, quien había llevado a cabo una extensa expedición hidrográfica entre el golfo de Maracaibo y el río Chagres en los albores del siglo XIX. Igualmente, Francisco José de Caldas es mencionado para la parte alta del Magdalena y José Manuel Restrepo para la provincia de Antioquia. En síntesis, Acosta tenía clara conciencia del amplio acervo de conocimientos que estaba implementando en la elaboración de su obra cartográfica, lo que revela en la nota incluida en la esquina superior derecha del mapa, donde apunta: "la discusion de los elementos que me han servido para la construcción de este mapa sería un tratado del estado actual de la Geografía de la Nueva Granada".

De otra parte, a la gran atención puesta a los componentes de la geografía física en el Mapa de la Nueva Granada, se suma un claro interés por la geografía política y el trazado de los límites granadinos, para entonces tan difusos y poco claros. Como se verá, en el campo de la geografía política este mapa tendrá una influencia visible sobre posteriores trazados cartográficos en el país. También es particularmente en ese terreno que Acosta actúa como cartógrafo-historiador.

\section{Las diferencias limítrofes en América Central y su expresión en el mapa de 1847}

Joaquín Acosta fue Secretario de Relaciones Exteriores de la Nueva Granada entre 1843 y 1845, cargo desde el que tuvo que afrontar la aparición de varias diferencias limítrofes -, algunas de las cuales, de una u otra forma, siguen vigentes en el país -, en particular en el área del Caribe, América Central y Venezuela. ${ }^{9}$ En respuesta a estas problemáticas, el enfoque adoptado por Acosta coincidió plenamente con la doctrina del Uti Possidetis Juris asumida por los Estados hispanoamericanos en el siglo XIX. Dicha doctrina, según la cual cada nueva nación conservaría "la posesión del territorio que de hecho tenía en 1810", lo condujo a recuperar archivos, ordenanzas y documentos geográficos de origen colonial, que permitieran sentar las bases jurídicas para el trazado de límites del país, siguiendo los lineamientos de las divisiones territoriales propias de la reorganización borbónica. ${ }^{10}$

Pero pese a la claridad que esta doctrina parecía suponer, su puesta en práctica llevó a que afloraran las contradicciones entre las aspiraciones geográficas de un Estado en ciernes, basadas en las delimitaciones políticas de finales de la colonia y su corta presencia en los espacios marginales de un territorio tan extenso y poblado, en las áreas de frontera, por comunidades indígenas dueñas de diferentes formas de territorialidad que, en ocasiones, mantenían contacto con los amplios intereses de potencias en ascenso como Gran Bretaña.

En efecto, el trazado del límite de la Nueva Granada en América Central, tal y como aparece trazado en el mapa de Acosta, estuvo precedido por una amplia polémica que expresó un repentino y efímero despertar de la conciencia geográfica sobre el Atlántico por parte del Estado granadino. Dicha polémica, referente a la discrepancia limítrofe entre 
Costa Rica y Nueva Granada, incluía varios lugares en disputa y, a grandes rasgos, condujo al gobierno granadino a reivindicar amplios territorios ubicados en el litoral Caribe centroamericano, situados hoy en Costa Rica y Nicaragua, así como las islas de San Andrés y Providencia. ${ }^{11}$ En ese sentido, es interesante observar que uno de los recuadros del mapa de Acosta hace referencia a la posición de la Nueva Granada respecto a las Antillas, Centroamérica y los países vecinos de América del Sur.

Veamos un poco cuáles eran las áreas en disputa en el Caribe: Costa Rica reclamaba como límite en el litoral Atlántico territorios hasta la isla del Escudo de Veragua, ${ }^{12}$ basándose en el territorio que había correspondido a la antigua Capitanía General de Guatemala. En el litoral Pacífico, reivindicaba una línea que terminaba en la Punta de Burica. Mientras tanto, Nueva Granada, a partir de una Real Cédula de $1803,{ }^{13}$ consideraba suyo el territorio de Bocas del Toro que incluía la costa de Mosquitos y todo el litoral hasta el Cabo de Gracias a Dios, así como derechos sobre las islas de San Andrés y Providencia. En el Pacífico, reclamaba las tierras hasta el río Golfito.

Pero mientras Costa Rica y Nueva Granada mantenían indefinidos sus límites, la presencia británica en el litoral caribe centroamericano se había fortalecido, lo que venía ocurriendo desde finales de la época colonial. Desde inicios del siglo XIX se sentía su influencia en el área, a través del apoyo a empresas de colonización y frecuentes intercambios comerciales con la población indígena de Mosquitos. En la década de 1840, el gobierno británico se mostró protector de la reclamación de soberanía por parte de la comunidad indígena, de hecho, en 1843 Gran Bretaña estableció oficialmente el "Protectorado de la Moskitia" que permaneció hasta 1860. Con ello silenciaba algunos de sus intereses, relacionados con la exploración de una vía para la construcción de un canal interoceánico a través del lago de Nicaragua.

Fue en este contexto que el gobierno granadino, a través de Acosta, reivindicó los territorios adjudicados a la Nueva Granada por la cédula real de 1803, basándose en argumentos jurídicos, pese a la escasa presencia estatal en el área de frontera. ${ }^{14}$ En una de sus comunicaciones Acosta afirmaba "Que el Gobierno de la Nueva Granada no reconoce ni ha reconocido nunca dentro de sus territorios, la existencia independiente de ninguna nación de indígenas salvajes; que ha sostenido y sostiene el señorío y dominio de la República sobre todos los territorios que le corresponden por haber sido adquiridos legítimamente de la España". ${ }^{15}$

Esta postura fue afirmada a través de un extenso ensayo titulado "Nuestras Costas Incultas"16 en el cual Pedro Fernández Madrid, quien trabajaba con Acosta en la Secretaría de Relaciones Exteriores, abordaba la temática de la soberanía territorial de la Nueva Granada en el Caribe. Allí, Madrid manifiesta la necesidad de mantener la jurisdicción sobre la región, afirmando el rol civilizador del Estado e impidiendo la declaración de autonomías por parte de las comunidades indígenas que la habitaban, lo cual aseveraba de la siguiente manera: "Si el dominio se reconociese a los salvajes, se cometería una grande inconsecuencia, como ya lo hemos manifestado: sería necesario renunciar a la civilización de estos individuos y resignarse a que la nación más fuerte o más atrevida se apoderase de su territorio".

En este punto, el aspecto que debe resaltarse es el cambio de perspectiva que se produce posteriormente en las negociaciones diplomáticas frente al tema y que se plasma claramente en el mapa de Acosta. Como se vio, la postura inicial del gobierno granadino reivindicaba derechos a lo largo de la costa atlántica hasta el Cabo de Gracias a Dios. Sin embargo, más adelante el concepto se transforma. Ante la presión externa ejercida por Gran Bretaña, el gobierno granadino reduce sus aspiraciones y como lo afirma Madrid, hacia el final de su texto, propone "ceder a los Estados de Centro América la porción de la Costa de Mosquito que se nos adjudicó por la Real Cédula de 1803, y, si fuere posible, obtener en compensación algún aumento a nuestra frontera en lo interior del Continente". ${ }^{17}$

En el nuevo proyecto limítrofe, el litoral granadino abarcaría solamente hasta la Provincia de Chiriquí -, hasta la desembocadura del Río Culebras en el Atlántico -, donde se ubicaba el límite del Virreinato de Nueva Granada antes de la expedición de la Real Cédula de 1803. Esto implicaba la cesión de la Costa de Mosquitos a las repúblicas centroamericanas, aunque manteniendo la soberanía sobre las islas de San Andrés y Providencia. De esta actitud podría interpretarse que Fernández Madrid consideraba recomendable ceder a Costa Rica la Costa de Mosquitos, antes que afrontar directamente el expansionismo inglés, o bien, como una posición que privilegiaba la necesidad de llegar a acuerdos entre los países hispanoamericanos, antes que abrir las puertas al ensanchamiento de la colonización británica en el Caribe. 
Los resultados de esta amplia discusión y el discurso sobre la "cesión" de áreas en América Central se vieron reflejados en la cartografía de mediados del siglo XIX. Es interesante notar que la cartografía asumió las posturas planteadas por Acosta tanto en sus labores diplomáticas como en su mapa de 1847, en el cual se ubica la frontera en la provincia de Chiriquí. En los diferentes trazados, el límite del territorio granadino se ubica en la desembocadura del Río Culebras en el Atlántico, y en el Golfo Dulce en el Pacífico. Los mapas presentan, en cambio, sutiles diferencias con respecto al punto en el que acaba la línea en el Golfo Dulce: Acosta y Mosquera la ubican en la Punta Burica, mientras Ponce y Paz la sitúan más hacia el centro del Golfo Dulce.

\section{El trazado de la frontera con Venezuela}

En el caso de la frontera con Venezuela, como bien lo expresa hacia la década de 1850 el venezolano Francisco Michelena y Rojas: "apénas se creería sin sorpresa y sin asombro, que dos pueblos hermanos como estos, escasamente poblados y habitando inmensas regiones desiertas, se disputen por la posesión de pedazos de tierra que ninguno sabe aprovechar". ${ }^{18}$ Efectivamente, luego de varias negociaciones infructuosas como aquella del tratado Pombo-Michelena (1833), en la década de 1840, Acosta trabajó en el trazado de una línea limítrofe desde un enfoque similar al utilizado para América Central.

A partir de varias Cédulas Reales enmarcadas en el contexto de las reformas borbónicas - las de 1768, 1786 y $1792-{ }_{1}^{19}$ construyó una propuesta sobre de línea fronteriza que puede resumirse de la siguiente manera: en la península de la Guajira, los límites granadinos debían extenderse hasta los confines de la jurisdicción de Sinamaica. ${ }^{20}$ Con ello, la península Guajira en su integridad quedaría bajo jurisdicción de la Nueva Granada. Sin embargo, Venezuela consideraba que la frontera debía situarse más al oeste, en el Cabo de la Vela, mientras que el tratado que se había redactado en 1833 (Pombo-Michelena) situaba el punto de partida de la línea en el Cabo de Chichivacoa, lugar intermedio entre ambas posturas.

Más al sur, en la zona de Santander, Acosta llevaba el límite hasta la jurisdicción de San Faustino. ${ }^{21}$ Luego, citando la Real Cédula de 1786, la línea debería ubicarse desde la embocadura del Río Meta hasta el Rionegro. Como puede verse, los lugares críticos de la delimitación coinciden con los llamados "Territorios especiales", como es el caso de la Guajira, donde es bien conocido que el área Wayúu buscó ser controlada hacia finales de la colonia desde villas como Sinamaica, considerada punto de avanzada en territorio étnico guajiro, así como, más al sur, el Territorio de San Martín y Casanare.

La lectura de los textos de geografía producidos durante el periodo liberal (1885), ${ }^{22}$ y la observación de los mapas del país elaborados por Mosquera (1852), Samper (1858), y Manuel Ponce y Manuel María Paz (1864) muestra que, en ellos, si bien con algunas variaciones, la frontera con Venezuela adopta un itinerario similar basado en las investigaciones histórico-geográficas y jurídicas de Acosta. Su postura en ese sentido tendió a ser dominante, con algunas variaciones, a través de la cartografía y el discurso geográfico granadino durante varias décadas.

El siguiente camino en dirección sur a norte es el trazado en dichos textos geográficos para la frontera con Venezuela: Río Negro - Brazo Casiquiari - Río Orinoco - Río Meta (hasta el punto llamado "El Apostadero") - Río Arauca y Arauquita (hasta el Desparramadero del Sarare) - Río Sarare o Río Macao o Río Nula - Río Táchira - Río de Oro - Serranía del Perijá - Cabeceras de los ríos Socui y Totolí - Límites con Sinamaica en la ensenada de Calabozo en el golfo de Maracaibo.

De esta forma, aunque para el momento no se había llegado a ningún acuerdo concluyente por ambos gobiernos acerca de la cuestión limítrofe, lo que no sucedería sino hasta principios del siglo XX, los mapas y las geografías granadinas a lo largo del periodo liberal expusieron una posición bastante homogénea, claramente influenciada por el enfoque y los planteamientos de Joaquín Acosta y plasmados en su Mapa de la Nueva Granada de 1847. 


\section{Algunas consideraciones finales}

Con nuestro artículo quisimos mostrar cómo el mapa de la Nueva Granada elaborado por Joaquín Acosta y editado en 1847, fue uno de los fundamentos sobre los cuales se construyeron otras cartas granadinas o colombianas del siglo XIX dedicadas a la representación del territorio nacional, lo que se expresa particularmente en la temática relativa a los límites políticos del país en el área de América Central y con Venezuela. Adicionalmente, planteamos que el método utilizado para la construcción de esta carta geográfica incorporó la compilación de medidas tomadas por el autor durante expediciones militares y trabajos de campo a lo largo de varias décadas, lo que complementó con el uso de diversas fuentes cartográficas, diarios de científicos y viajeros, así como con la recuperación de ordenanzas reales de finales del periodo colonial, con el propósito de establecer los límites territoriales de acuerdo con la doctrina del uti possidetis juris.

La indagación y lectura rigurosa de documentos cartográficos, geográficos y legales de las últimas décadas del periodo colonial y su uso para la construcción del mapa de 1847, es uno de los rasgos en los que consideramos se expresa una confluencia de su práctica como cartógrafo y con algunas de las prácticas que caracterizaron la labor del historiador en el siglo XIX. Dada la importancia que ambos oficios tuvieron en la vida de Joaquín Acosta, sería de gran interés para futuras investigaciones hacer una lectura en el sentido inverso, es decir, acerca de los elementos cartográficos y geográficos presentes en su obra historiográfica, sobre lo cual puede señalarse como elemento visible que en el Compendio histórico del descubrimiento y colonización de la Nueva Granada en el siglo décimosexto (1848), se incluye un mapa de las rutas de los conquistadores en el territorio granadino preparado por Acosta.

De otro lado, es importante poner de relieve otras pistas que será necesario explorar en posteriores trabajos: la primera de ellas es que entre los mapas de mediados del siglo XIX, hay uno en particular que no incluye explícitamente entre sus fuentes el elaborado por Acosta o bien parece silenciarlo. Se trata de la Carta de la república de la Nueva Granada (1852) de Tomás Cipriano de Mosquera, trabajada particularmente a partir del mapa de Colombia publicado por Agustín Codazzi en el Atlas de Venezuela. Sin embargo, se sabe que Mosquera conoció y analizó detalladamente el mapa de Acosta pues éste lo hizo llegar a la presidencia justamente en un momento en que Mosquera era presidente de la república (1845-1849). ${ }^{23}$ Es así como, además del uso y las referencias explícitas, la omisión de autores y fuentes puede ser un ámbito de interés para continuar las indagaciones en el ámbito de la historia de la cartografía, como ha señalado J. B. Harley. ${ }^{24}$

En segundo lugar, precisamente en relación con el tema del límite en el sur y suroriente del país, sucede algo bien diferente a lo ocurrido acerca del trazado de las fronteras en América central y Venezuela. De hecho, la propuesta hecha por el mapa de Acosta sobre el trazado de la frontera con Ecuador, Perú y Brasil, fue objetada o bien refutada por la cartografía de mediados del siglo XIX, incluyendo en el mapa que se supone es una copia adaptada al sistema federal, es decir el de José María Samper de 1858. De hecho, cada uno de los mapas tiene una propuesta bien diferente sobre este punto, lo que de alguna manera responde al hecho de que las negociaciones, por ejemplo, con Brasil no se iniciaron sino más adelante luego de la década de 1850.

\section{Notas e referências bibliográficas}

Lucía Duque Muñoz é doutora em História pela Universidade de Toulouse, França, e professora assistente do Departamento de História da Universidade Nacional da Colômbia. E-mail: duquetoul@gmail.com.

1 ACOSTA, Joaquín. Compendio histórico del descubrimiento y colonización de la Nueva Granada en el siglo décimo sexto. París: Imprenta de Beau, 1848. p. xvi.

2 Francisco José de Caldas fue uno de los naturalistas, geógrafos y cartógrafos criollos de mayor importancia a lo largo de las décadas de finales del periodo colonial y principios del proceso independentista en la Nueva Granada. Inició sus trabajos como naturalista durante la Expedición botánica al lado de 
José Celestino Mutis, asímismo, editó y escribió numerosos ensayos de carácter geográfico y científico para el Semanario del Nuevo Reino de Granada. Además de sus investigaciones botánicas y geográficas, estaba en proceso de elaborar un Atlas de la región, que desafortunadamente quedó inacabado al ser asesinado en 1816 durante la reconquista española. Ver: NIETO, Mauricio; MUÑOZ, Santiago; DíAZ P., Santiago; ARIAS DE GREIFF, Jorge. La obra cartográfica de Francisco José de Caldas. Bogotá: Universidad de los Andes, Academia Colombiana de Ciencias Exactas, Físicas y Naturales, 2006.

3 Los límites actuales de Colombia fueron refrendados mediante los siguientes convenios: con Ecuador el Tratado Suárez-Muñoz Vernaza (15 de julio de 1916); con Perú el Tratado Lozano-Salomón (24 de marzo de 1922) y Protocolo de Rio de Janeiro (24 de mayo de 1934); con Brasil los Tratados Vásquez Cobo- Martins (24 de abril de 1907) y García Ortiz-Mangabeira (15 de noviembre de 1928); con Venezuela el Laudo Español (16 de marzo de 1891), Arbitramento suizo (24 marzo de 1922) y Tratado López de Mesa-Gil Borges (1941); y con Panamá el Tratado Vélez-Victoria (20 de Agosto de 1924). Atlas de Colombia. Bogotá: Instituto Geográfico Agustín Codazzi - IGAC, 2000. p. 3.

BROC, Numa. La géographie des philosophes. Géographes et voyageurs francais au XVIIle siècle. Paris: Ophrys, 1975. p. 476.

5 La biografía del General Acosta por su hija contiene un largo apartado basado en los diarios que llevaba su padre. Allí cuenta detalladamente las diversas misiones militares que cumplió Acosta en el Chocó y sus permanentes recorridos de los Río Atrato, San Juan, Tamaná, Habitá e Ingará. ACOSTA DE SAMPER, Soledad. Biografía del general Joaquín Acosta. Bogotá: Librería Colombiana Camacho, Roldán y Tamayo, 1901. p. 34-52.

6 ACOSTA, op. cit., 1848, p. vi. Joaquín Céspedes era un reconocido botánico granadino.

7 La llamada "Misión Zea" debe su nombre a Francisco Antonio Zea, botánico granadino que en 1822 organizó el ingreso a la Nueva Granada de un grupo de científicos, entre ellos varios franceses y un peruano, con el propósito de que hicieran investigaciones mineralógicas y fundaran un Museo de Historia Natural en el país.

8 DUQUE MUÑOZ, Lucía. Territorio nacional, cartografía y poder en la Nueva Granada a mediados del siglo XIX. Les Cahiers ALHIM. Amérique Latine, Histoire et Mémoire. Paris, n. 15, p. 119-137, 2008. En dicho artículo se hace un análisis comparativo de la construcción del mapa de Acosta y de otros mapas nacionales elaborados a mediados del siglo XIX en el país, como la Carta de la República de la Nueva Granada (1852) hecha por Tomás Cipriano de Mosquera y la Carta Jeográfica de los Estados Unidos de Colombia (1865) dibujada por Manuel María Paz y Manuel Ponce de León a partir de los trabajos de Agustín Codazzi y la Comisión Corográfica de la Nueva Granada.

9 Para comprender con mayor detenimiento esta problemática, ver: DUQUE MUÑOZ, Lucía. El discurso geográfico y cartográfico colombiano sobre los límites entre Nueva Granada y Venezuela: 1830-1883. Anuario Colombiano de Historia Social y de la Cultura. Bogotá, v. 36, n. 1, p. 125-152, 2009.

10 RIVAS, Raimundo. Escritos de don Pedro Fernández Madrid. Bogotá: Minerva, 1932. p. 188-302.

11 DUQUE MUÑOZ, Lucía. Límites de la Nueva Granada en Centroamérica: la polémica con Gran Bretaña en torno a la posesión de la Costa de Mosquitos a mediados del siglo XIX. Boletín de la AFEHC. Toulouse, 2005. Disponível em: <http://afehc-historia-centroamericana.org/index.php?action=fi_ affgid $=362>$.

12 Isla del Escudo de Veragua o del Escudo de Nicuesa, ubicada en el Océano Atlántico, frente a Bocas del Toro.

13 PERALTA, Manuel M. de. Costa Rica y Colombia de 1573 a 1881. Su jurisdicción y sus límites territoriales. Madrid y Paris: Librería de M. Murillo y Ernest Leroux, 1886. p. 280.

14 RIVAS, op. cit., 1932, p. 176

15 RIVAS, op. cit., 1932, p. 176

16 RIVAS, op. cit., 1932, p. 204-236.

17 RIVAS, op. cit., 1932, p. 277.

18 MICHELENA Y ROJAS, Francisco. Exploración oficial. Perú: CETA - IIAP, 1989. p. 415.

19 LONDOÑO PAREDES, Julio. Derecho territorial colombiano. Bogotá: Imprenta de las fuerzas militares, 1973. p. 62.

20 Laguna formada por el Río Limón y ubicada en el límite con la vecina República de Venezuela en la península Guajira.

21 Aldea ubicada en el Departamento de Santander, situada en un llano cerca del río Pamplonita a 150 metros sobre el nivel del mar.

22 A partir de la década de 1860 un gran número de los textos de geografía que salieron a la luz en el país fueron escritos o reeditados por Felipe Pérez, cuyo trabajo se basa mayoritariamente en los trabajos de Agustín Codazzi y la Jeografía física i política de las provincias de la Nueva Granada por la Comisión Corográfica (1851-1859).

23 Adicionalmente, en la Gaceta Oficial se publicó un artículo atribuido a Mosquera en el cual se hace una crítica detallada de varios elementos del mapa de Acosta, con especial énfasis en el trazado de la frontera sur de la Nueva Granada.

24

HARLEY, J. B. Deconstructing the map. Cartographica, v. 26, n. 2, p. 1-20, 1989.

[ Artigo recebido em 10/2011 | Aceito em 04/2012] 